Egyptian

Orthodontic Journal

\title{
EVALUATION OF THE CONNECTICUT INTRUSION ARCH IN LEVELING DEEP CURVE OF SPEE
}

\author{
Ahmed Abd El Kader El Beali ${ }^{1}$, Ahmad Mohammad Hafez ${ }^{2}$ \\ Hala Abdullah El - Sayed Badr ${ }^{3}$
}

\section{ABSTRACT:}

The Aim of the present study was to evaluate the suitability of Nitanium Connecticut intrusion arch in leveling deep curve of Spee. The sample of this study consisted of 10 Class II division 1 growing female patients with a mean age of 13.28 ( \pm 1.43 ). Lower short $0.017 \times 0.025$ inch nitanium Connecticut intrusion arches were used for all patients after the teeth had been initially aligned. Superimposition of lateral cephalograms taken before and after leveling for each patient was made to determine the anteroposterior and vertical displacement of the lower incisors as well as the vertical position displacement of lower first molar. Statistical paired $t$ - test was done to determine significant difference between the pre-leveling and post-leveling measurements. In the present study the lower incisors were significantly intruded by $2.63 \mathrm{~mm}$ in 5.2 months $(\mathcal{P}<0.001)$. Significant lower incisors proclination as indicated by the increase in the angle of the axis of the most protruded lower incisor to the Mandibular plane (MP), Frankfort horizontal plane (FH) and $\mathcal{N} B$ Plane by $3.5^{\circ}, 4.125^{\circ}$, $2.625^{\circ}$ respectively $(P<0.001)$ as well as the increase in the distance from Ii to $\mathcal{N} B$ line by $1.688 \mathrm{~mm}$. There was also a significant decrease in the amount of overbite by $2.813 \mathrm{~mm}(\mathcal{P}<0.001)$. Mandibular

1- Professor \& Chairman of Orthodontic Department Faculty of Dentistry, Mansoura University.

2- Lecturer of Orthodontics, Faculty of Dentistry, Mansoura University.

3- Dentist at Students Hospital, Mansoura University. 
Lower first molars vertical position was not significantly changed (0.625mm $P$ > 0.05). As well as no significant change in the following measurements; lower facial height $(0.5 \mathrm{~mm} P>0.05)$, posterior facial height $(0.365 \mathrm{~mm} \mathscr{P}>0.05)$ and the FMA angle $(0.375 \mathrm{~mm} \mathbb{P}>0.05)$. It was determined that the Connecticut intrusion arch was effective in intrusion of lower incisors.

\section{INTRODUCTION}

Deep overbite is a common condition in adults. ${ }^{(1)}$ Because of potentially detrimental effects on mandibular and temporomandibular joint functions, ${ }^{(2,3,4)}$ and periodontal health ${ }^{(5)}$ as well as for esthetic reasons, ${ }^{(6)}$ deep overbite correction is often a major component of orthodontic treatment.

The primary determining factor in leveling deep curve of Spee in deep bite cases is to decide whether leveling requires intrusion of anterior teeth, extrusion of posterior teeth or combination of both. This requires a study of lip relationships, vertical facial relationship, occlusal plane, A-B discrepancy and the age of the patient. Then leveling can be accomplished using removable or fixed appliances through several different techniques. ${ }^{(7)}$

Begg and Kesling ${ }^{(8)}$, Ricketts ${ }^{(9,10)}$ and Burstone ${ }^{(11)}$ described numerous methods for incisor intrusion, however they have been employed the same basic principle: (tipback bends at the molars to provide an intrusive force at the incisors). The wire materials and thickness used for intrusion in these techniques are diverse, but all recognize the need for a light, continuous force.

Inability to produce genuine intrusion is one of the main limitations of the traditional continuous arch therapy. ${ }^{(12)}$ Titanium alloys are currently the materials of choice for delivering light, continuous forces under large activations, as these alloys have high memory and low load-deflection rates, they produce small increments of deactivation over time and thus reducing the number of reactivation appointments. ${ }^{(13,14)}$

The nickel-titanium intrusion arch (CIA) wires are available in: two dimensions $(0.016 \times 0.022$ and $0.017 \times 0.025)$. The maxillary and mandibular versions have anterior dimension of $34 \mathrm{~mm}$ and $28 \mathrm{~mm}$ respectively. It is 
provided with comfort steps allowing the wire to bypass the canine and premolar brackets, when inserted into the molar auxiliary tube. The posterior dimension is available in two different lengths to accommodate for extraction, non extraction and mixed dention cases. Once the intrusion arches inserted, the preactivation bend is located anterior to the molar tube. ${ }^{(15)}$

\section{MATERIALS AND METHODS}

The sample of this study consisted of 10 female patients ranging in age from 11 to 14 years old with a mean age of $13.28( \pm 1.43)$. They were selected from the Clinic of Orthodontic Department, Faculty of Dentistry, Mansoura University.

Each subject of the sample had to fulfill the following criteria: Class II Angle classification indicated for treatment with extraction of the first premolars; Deep overbite (more than $4 \mathrm{~mm}$ ) manifested with deep curve of Spee in the lower arch; Frankfort-Mandibular plane angle (FMA) was $\geq 30$ degrees; All permanent teeth except (third molars) were present.

Appliance Design: The mandibular Connecticut intrusive arch has anterior dimension of $28 \mathrm{~mm}$. It is provided with comfort steps allowing the wire to bypass the canine and premolar brackets, when being inserted into the molar auxiliary tube. The posterior dimension is $15 \mathrm{~mm}$ to accommodate for extraction cases. Once the intrusion arches inserted, the preactivation bend is located anterior to the molar tube.

\section{Preparation of the Patient for Intrusive Mechanics:}

Soft tissue evaluation for each patient was done in three different clinical situations; in relaxed lip position, while smiling and during $\operatorname{speech}^{(16)}$

The intrusive mechanics included:

- Posterior anchorage unit consisted of lingual arch joining the lower second premolar and lower first molar stabilized with $0.017 \times 0.025$ inch stainless steel rectangular wire on both sides.

- Anterior unit; that include the lower four incisors bracketed with fixed pretorqued and preangulated 0.022 inch slot edge wise brackets (Nanda prescription) joined together with $0.017 \times 0.025$ inch stainless steel rectangular wire.

- The Connecticut intrusive arch. 
Egyptian

Orthodontic Journal

\section{1) Alignment stage:}

After extraction of the mandibular first premolars, both anterior and posterior segments were initially aligned (according to Nanda arch wire selection to accommodate the use of 0.022 arch wire slot bracket) with $0.014,0.016$, and $0.016 \times 0.022$ inch Nickel titanium arch wires then $0.016 \times 0.022$ and $0.017 \times 0.025$ inch stainless steel arch wires were inserted. ${ }^{(17)}$ The $0.017 \times 0.025$ inch stainless steel stabilizing arch was then sectioned just mesial to the lower canine and second premolar brackets. The mandibular second premolar and first molar were then laced together.

2) The Connecticut intrusion arch (CIA) insertion:

- The selected intrusion arch was lower short 0.017 x 0.025 inch readymade nitanium CIA, inserted into the lower first molar auxiliary tube with the "V" bend located anterior to the molar tube thus the intrusion arch would be in the vestibular sulcus.

- Activation was done by lifting up the intrusion arch occlusally and tying it to the anterior segment between the central incisors and distal to the lateral incisors by ligature wire, so that the intrusive force passes through the center of resistance.

- The force gauge was also used in the mouth to measure the applied force.

- The total intrusive force used was $60 \mathrm{gm}$ (i.e.15 gm per tooth).

- The excess wire protruded from lower molar auxiliary tube is cut off leaving approximately $3 \mathrm{~mm}$ of wire distal to tube for cinch back (a sharp bend distal to the auxiliary molar tube); to prevent forward slippage of wire that could result in undesirable incisor flaring during intrusion.

- A tight cinch back was done by flaming the posterior ends of intrusion arch thus decreasing the elasticity of the wire and rendering it more bendable then the wire was hold with a ligature director and twisted sharply toward gingival. 
- After intrusion of lower incisors was completed, it is possible to intrude the lower canines by inserting a base arch wire into the teeth brackets and then the CIA intrusion arch is tied anteriorly between the central incisors and distal to the lateral incisors. ${ }^{(15,16,17)}$

- Canine retraction was done if needed on a base arch wire, with the CIA intrusion arch tied anteriorly to prevent extrusion of lower incisors and relapse of the deep bite that could occur during canine retraction. $^{(30)}$

3) Finishing the deep bite correction stage:

Intrusion was utilized until leveling deep curve of Spee is completed which could be assessed both clinically as well as through pre and post-dental casts. Then all the wires were removed from teeth and final records were taken to evaluate the results. Then treatment was completed for all the cases.

Records: For each patient the following diagnostic records were taken before and after the leveling stage:

- Photographs (intraoral, extraoral).

- Upper and lower orthodontic casts.

- Radiographs (Lateral cephalometric, Panoramic and left hand wrist radiographs).

All records were taken before and after treatment except the hand wrist and panoramic x-ray films which were taken only before treatment.

Superimposition of cephalograms taken before and after leveling for each patient was made at the anterior cranial base i.e. it is done on SN line keeping (S) Sella as a registration point, which had been reported to be relatively stable. ${ }^{(18)}$ Mandibular superimposition was also carried out at the symphysis and the anterior third of the lower border of the mandible to determine the anteroposterior and vertical displacement of the lower incisors as well as lower first molar vertical position displacement. 


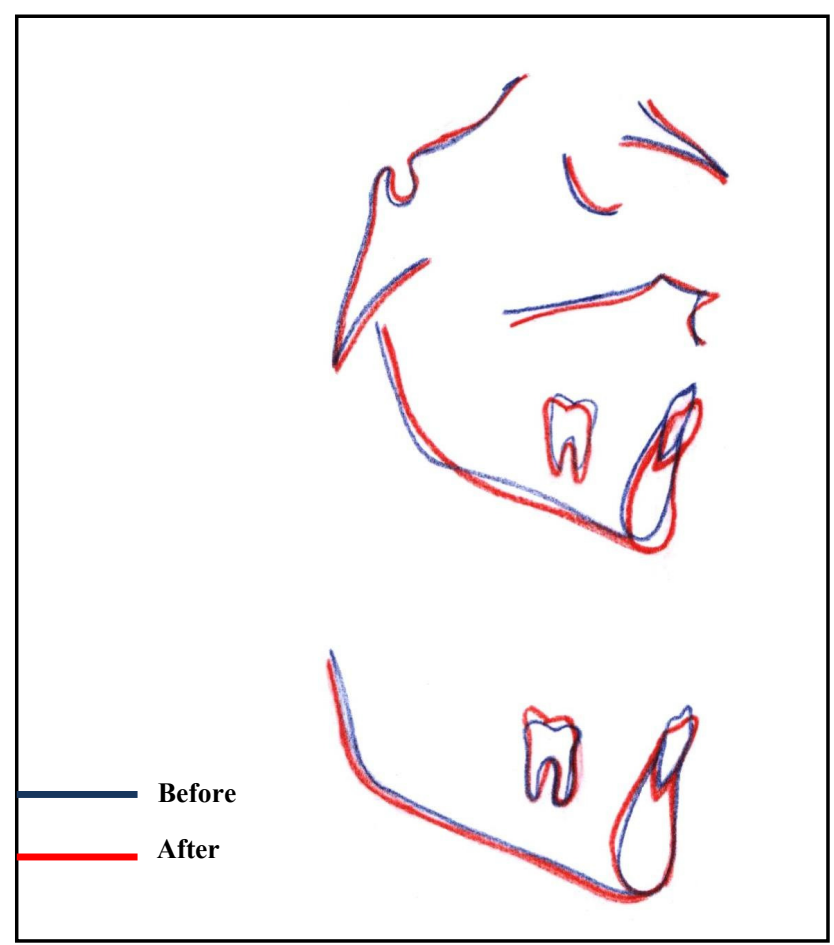

Figure1: Superimposition on: A- anterior cranial base, B- symphysis and anterior third of lower border of the mandible showing; lower incisor vertical and anteroposterior position changes as well as molar vertical position changes.

\section{RESULTS}

The Connecticut intrusive arch had dental and skeletal effects as follow; The Lower incisors were significantly intruded by $2.63 \mathrm{~mm}$ in 5.2 months $(\mathrm{P}<0.001)$. significant lower incisors proclination as indicated by the increase in the angle of the axis of the most protruded lower incisor to the Mandibular plane (MP), Frankfort horizontal plane (FH) and NB Plane by $3.5^{\circ}, 4.125^{\circ}$, $2.625^{\circ}$ respectively $(\mathrm{P}<0.001)$ as well as the increase in the distance from Ii to NB line by $1.688 \mathrm{~mm}$. There was also a significant decrease in the amount of overbite by $2.813 \mathrm{~mm}(\mathrm{P}<0.001)$. Mandibular lower first molars vertical position was not significantly changed $(0.625 \mathrm{~mm} \mathrm{P}>0.05)$. As well as no significant change in the following measurements; lower facial height $(0.5 \mathrm{~mm} \mathrm{P}>0.05)$, posterior facial height $(0.365 \mathrm{~mm} \mathrm{P}>0.05)$ and the FMA angle $(0.375 \mathrm{~mm} \mathrm{P}>0.05)$. 
Table (1): Changes in the lower incisors antero-posterior position measurements before and after leveling stage.

\begin{tabular}{|l|c|c|c|c|c|c|c|c|}
\hline \multirow{2}{*}{\multicolumn{1}{c}{ Measurements }} & \multicolumn{2}{|c|}{ Pretreatment } & \multicolumn{2}{c|}{ Post treatment } & \multicolumn{2}{c|}{ Changes } & \multicolumn{2}{c|}{ Significance } \\
\cline { 2 - 10 } L1/MP (degrees) & Mean & SD & Mean & SD & Mean & SD & t & p \\
\hline L1/FH plane (degrees) & 93.5 & \pm 7.151 & 97 & \pm 7.578 & 3.5 & \pm 0.535 & 18.52 & $0.000^{* *}$ \\
\hline L1/NB (degrees) & 29.13 & \pm 5.249 & 31.75 & \pm 4.892 & 2.625 & \pm 0.916 & 8.104 & $0.000^{* *}$ \\
\hline Ii to NB (mm) & 6.63 & \pm 2.761 & 8.31 & \pm 2.939 & 1.688 & \pm 0.53 & 9 & $0.000^{* *}$ \\
\hline
\end{tabular}

** High Significant $\mathrm{P}<0.001$

Table (2): Changes in the lower incisors vertical position measurements before and after leveling stage.

\begin{tabular}{|l|c|c|c|c|c|c|c|c|}
\hline \multirow{2}{*}{ Measurements } & \multicolumn{2}{|c|}{ Pretreatment } & \multicolumn{2}{c|}{ Posttreatment } & \multicolumn{2}{c|}{ Changes } & \multicolumn{2}{c|}{ Significance } \\
\cline { 2 - 9 } & Mean & SD & Mean & SD & Mean & SD & t & p \\
\hline Ii to MP (mm) & 43.32 & \pm 4.123 & 40.69 & \pm 4.217 & 2.63 & \pm 0.598 & 9.466 & $0.000^{* *}$ \\
\hline Overbite (mm) & 5.69 & \pm 0.961 & 2.57 & \pm 0.694 & 3.12 & \pm 0.799 & 9.956 & $0.000^{* *}$ \\
\hline
\end{tabular}

** High Significant $\mathrm{P}<0.001$

Table (3): Change in lower first molar vertical position measurement before and after the leveling stage.

\begin{tabular}{|c|c|c|c|c|c|c|c|c|}
\hline \multirow{2}{*}{ Measurements } & \multicolumn{2}{|c|}{ Pretreatment } & \multicolumn{2}{c|}{ Post treatment } & \multicolumn{2}{c|}{ Changes } & \multicolumn{2}{c|}{ Significance } \\
\cline { 2 - 9 } & Mean & SD & Mean & SD & Mean & SD & t & p \\
\hline Mi to MP (mm) & 29.38 & \pm 2.341 & 30 & \pm 2.204 & 0.625 & \pm 0.694 & 2.546 & 0.38 \\
\hline
\end{tabular}

$\mathrm{NS}=$ Not significant $\mathrm{P}>0.05$

Table (4): Changes in skeletal measurements before and after the leveling stage.

\begin{tabular}{|l|c|c|c|c|c|c|c|c|}
\hline \multirow{2}{*}{ Measurements } & \multicolumn{2}{|c|}{ Pretreatment } & \multicolumn{2}{c|}{ Post treatment } & \multicolumn{2}{c|}{ Changes } & \multicolumn{2}{c|}{ Significance } \\
\cline { 2 - 9 } & Mean & SD & Mean & SD & Mean & SD & t & p \\
\hline ANS to Me (mm) & 66.5 & \pm 5.73 & 67 & \pm 6.279 & 0.5 & \pm 1.12 & 1.183 & $0.275^{* *}$ \\
\hline S to Go(mm) & 76.63 & \pm 3.11 & 76.25 & \pm 2.55 & 0.365 & \pm 1.06 & 1 & $0.351^{*}$ \\
\hline FMA (degrees) & 34.38 & \pm 5.13 & 34.75 & \pm 5.23 & 0.375 & \pm 1.24 & 0.6 & $0.567 *$ \\
\hline
\end{tabular}

* NS $=$ Not significant $\mathrm{P}>0.05$ 

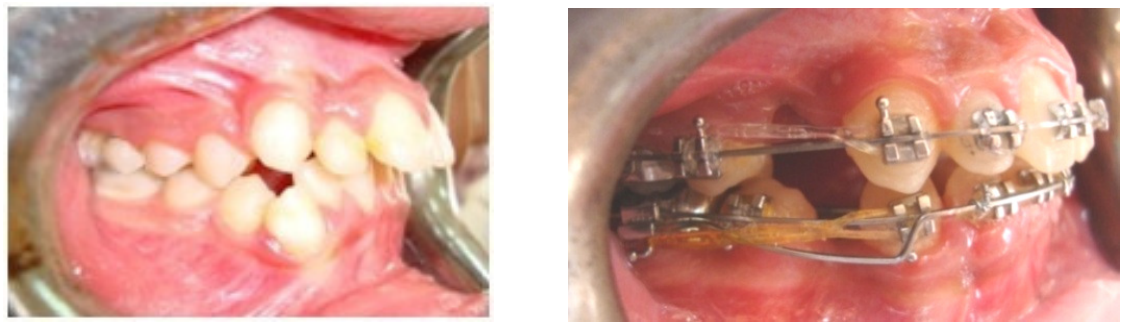

Figure2: Intraoral view before and after leveling stage showing; canine retraction was proceeded with the Connecticut intrusion arch tied to the base arch wire distal to lateral incisors and between central incisors.

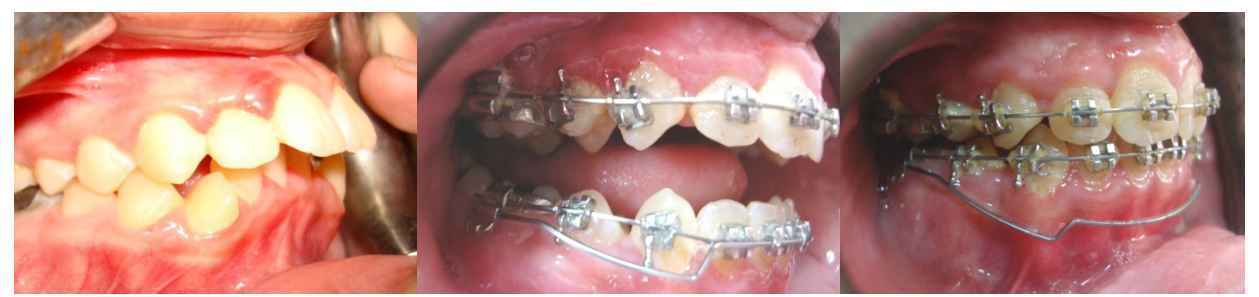

Figure3: Intraoral view before and after leveling stage showing; canine intrusion and retraction was proceeded with the Connecticut intrusion arch tied to the base arch wire distal to lateral incisors and between central incisors.
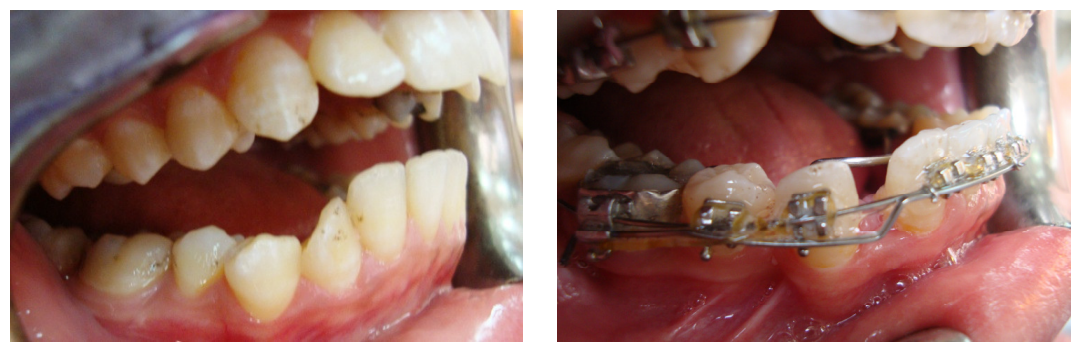

Figure4: Intraoral view before and after leveling stage showing; canine intrusion and retraction was proceeded with the Connecticut intrusion arch tied to the base arch wire distal to lateral incisors and between central incisors.

\section{DISCUSSION}

Intrusion of the anterior teeth is one of the treatment modalities available for the correction of deep overbite through various intrusion mechanics that have been introduced. $(7,9,10)$ 
A literature review indicated different opinions regarding the amount of force for intrusion of incisors and usually light, continuous forces were stated to be more suitable (10-15 gm per incisor tooth). ${ }^{(9,19)}$

Compared to continuous wire activations, segmented springs exert forces in a range greater than the intended tooth movement; this might be known as (Force constancy/load deflection rate). The deflection of the spring engaged to the incisors exceeds the amount of overbite correction. This feature both reduces the magnitude of the applied force and improves its constancy. A more continuous, low force allows increased time intervals between adjustments and may be gentler on the responding tissues. ${ }^{(19)}$

In the present study, the extent of lower anterior teeth intrusion found was $2.63 \mathrm{~mm}$ in a mean period of 5.2 months with SD of \pm 0.83 (range of time was 4 to 6 months) and the rate of intrusion per month was $0.51 \mathrm{~mm}$ which corresponds with those found in the previous studies of both Weiland et al ${ }^{(20)}$ and Goerigk ${ }^{(21)}$ who used segmented bite opening mechanics, as recommended by Burstone. Weiland et al ${ }^{(20)}$ found that lower incisor intrusion was $1.71 \mathrm{~mm}$ in 4 months and the rate of intrusion per month was $0.42 \mathrm{~mm}$. Goerigk and Wehrbein $^{(21)}$ study reported an average of lower incisors intrusion of 2-3 mm for a mean period of 4.3 months and the rate of intrusion per month was $0.54 \mathrm{~mm}$. Several authors ${ }^{(22,23,24)}$ mentioned that it is reasonable to expect about $2 \mathrm{~mm}$ of incisor intrusion.

Amasyali ${ }^{(25)}$ made a study to examine and compare the effects of two different arches, the Nitanium Connecticut intrusion arch and the utility intrusion arch in a period of 6 months. Statistical evaluation of lateral cephalograms revealed that the upper incisors were intruded by $3.1 \mathrm{~mm}$ in the Connecticut intrusion arch group (the rate of intrusion per month was $0.52 \mathrm{~mm}$ ) and by 2.4 in the utility intrusion arch group (the rate of intrusion per month was $0.4 \mathrm{~mm}$ ). Also Nanda et al ${ }^{(7)}$ stated that about $1 \mathrm{~mm}$ of intrusion can be expected every six weeks.

From screening of the cephalometric superimpositions, the amount of intrusion seen ranged from 1-3 mm. In addition to individual biologic reactions, this might be due partially to different amounts of intrusive tooth movement that was needed in individual patients. 
Lower incisors in the present study were not only intruded but they were protruded and labially tipped also as indicated by the increase in the angle of the axis of the most protruded lower incisor to the Mandibular plane (MP), Frankfort horizontal plane (FH) and NB Plane by $3.5^{\circ}$, $4.125^{\circ}, 2.625^{\circ}(\mathrm{P}<0.001)$ as well as the increase in the distance from Ii to NB line $1.688 \mathrm{~mm}$. These findings are in accordance with many authors $^{(25,26,27,28)}$. Although the intrusive arch was cinched back, it applied an intrusive force with a clockwise moment, which tended to flare the incisors. This may also indicate that the point of force application used was in front of the center of resistance although the intrusive CTA arch is tied to the anterior segment between the two lower centrals and just distal to the lateral incisors. The center of resistance of the four incisors is usually estimated to be halfway between the crest of the alveolar bone and the apex of the lateral incisor root in the sagittal plane, intrusive forces passed through this center of resistance were expected to produce pure intrusion. ${ }^{(29)}$

Overbite decreased significantly by $3.12 \mathrm{~mm}$ and the decrease was more than the amount of intrusion of the anterior teeth, so we can conclude that not only the intrusion of the anterior teeth but also their labial proclination and to some extent relative extrusion of molars were effective in the treatment of deep overbite, these findings are in accordance with Amasyali ${ }^{(25)}$, where the overbite was reduced by $3.8 \mathrm{~mm}$ in the Connecticut intrusion arch group and by $3.2 \mathrm{~mm}$ in the utility intrusion arch group.

In relation to overbite reduction, it is important to note that proponents such as Burstone ${ }^{(11)}$ and Schrof ${ }^{(29)}$ recommended that no more than the four incisors should be included in the intrusive segment, as this might shift the anchorage balance toward distal tipping of the buccal segment. Nanda ${ }^{(19)}$ recommended the exclusion of the canines from the buccal segment because of the combination of the tip back rotation and extrusion is magnified on teeth mesial to the molar tube. Uribe and $\mathrm{Nanda}^{(30)}$ stated that in deep bite cases that require extraction of first premolars, canine retraction generates extrusive effect on incisors and to counteract this tendency, intrusion arch is tied anteriorly at the level of lateral incisors after the intrusion of incisors is completed to deliver 
Egyptian

Orthodontic Journal

a distal crown tipback moment on the molars, so as to effectively control the loss of distal anchorage often associated with sliding mechanics. With an intrusive force on the incisors and a moment on the molars, the base archwire will not deflect too much, as seen in sliding mechanics due to the friction generated by canine retraction.

No significant change in the vertical position of the mandibular first molar was found in this study $(0.625 \mathrm{~mm})$. This outcome was in agreement with the previous study of Weiland et $\mathrm{al}^{(20)}$ on the segmented arch technique of Burstone, where the vertical position of the lower molars showed little extrusive movement $(0.56 \mathrm{~mm}, \mathrm{P}<0.01)$,because he used additional anchorage mechanics to prevent molar extrusion.

Based on the results founded by Nanda ${ }^{(19)}$, there was some degree of anchorage loss due to the molar tip back moment that produce a significant amount of distal molar movement. The magnitude of this moment is calculated by multiplying the distance between the molar tube and the point of attachment at the incisors. The span between these points varies based on the clinical situation, but frequently ranges between 25 and $40 \mathrm{~mm}$. With an intrusive force of $40 \mathrm{~g}$, the tip back moment acting on the molars may range from 1000 to $1600 \mathrm{~g}$-mm. Increasing the number of teeth in the posterior anchorage unit (first molar to first premolar) with passive heavy segments as well as the inclusion of lingual arch, enhance the anchorage and helps to reduce the posterior effects of the intrusion arch.

The lower anterior facial height (ANS to Me), posterior facial height ( $\mathrm{S}$ to Go) and FMA angle showed non significant change in this study $\left(0.5 \mathrm{~mm}, 0.365 \mathrm{~mm}\right.$ and $0.375^{\circ}$ respectively, $\left.\mathrm{P}<0.05\right)$. This may be due to the non-significant change in the vertical position of the molars. This change is in agreement with the observations of Amasyali ${ }^{(25)}$, Weiland et $\mathrm{al}^{(20)}$ and Cakirer. ${ }^{(27)}$

\section{CONCLUSIONS}

1) With intrusion mechanics, the spring design provided: the ability to measure the magnitude of force, force constancy, the point of force application, and the molar tipback moment. 
2) Its simplicity of design and minimal requirement for additional adjustment made it an ideal addition to the armamentarium of the busy clinician.

3) The Connecticut intrusive arch was effective in reduction of deep overbite not only by intrusion itself but also by incisor flaring and molar extrusion as well.

\section{REFERENCES}

1 - Thilander B. Indications for orthodontic treatment in adults. In: Thilander B, Rtnuing O, eds. Introduction to orthodontics. Stockholm Tandlakarforlaget, 1985:235-52.

2 - Alexander TA, Gibbs CH, Thompson WJ. Investigation of chewing pattern in deep-bite malocclusions before and after orthodontic treatment. Am J Orthod 1984; 85:21-7.

3 - Perry HT. Mandibular function: an orthodontic responsibility. Am J Orthod 1975; 67: 316-23.

4 - Thompson JR. Differentiation of functional and structural dental malocclusion and its implication to treatment. Angle Orthod 1972; 42:252-62.

5 - Gould MSE, Picton DCA. The relation between irregularities of the teeth and periodontal disease: a pilot study. Br Dent J 1966; 121:20-3.

6 - Janzen EK. A balanced smile-A most important treatment objective. Am J Orthod 1977; 72:359-72.

7 - Nanda R. The Differential Diagnosis and Treatment of Excessive Overbite. In : Nanda R, ed. Symposium on Orthodontics, 1981;69:82.

8 - Begg PR, Kesling PC. Begg orthodontic theory and technique. Philadelphia: W B Saunders, 1977: 203-14.

9- Ricketts RM. Bioprogressive therapy as an answer to orthodontic needs. Part I. Am J Orthod 1976; 70:241-68.

10 - Ricketts RM. Bioprogressive therapy as an answer to orthodontic needs. Part II. Am J Orthod 1976; 70:359-97. 
Egyptian

Orthodontic Journal

11 - Burstone CJ. Deep overbite correction by intrusion. Am J Orthod 1977;72:1-22.

12- Burstone CJ. Rational of the segmented arch. Am J Orthod 1962; 48:805-22.

13 - Burstone CJ. Variable modulus orthodontics. Am J Orthod 1981; 80:1-16.

14 - Kusy RP. A review of contemporary arch wires: Their properties and characteristics. Angle Orthod 1997; 67:197-208.

15 -Nanda R, Marzaban R, Kuhlberg A. The Connecticut intrusion arch. J Clin Orthod 1998; 35: 708-15.

16- Nanda R, Upadhyay M. Etiology, diagnosis and treatment of deep overbite. In: Nanda R, Kapila S, eds. Current therapy in orthodontics. St Louis Mosby, 2010:186- 90

17- Nanda, R: Nanda biomechanical appliance system, pre programmed, preformed biomechanical bracket and wire systems: ortho organizers "advancing the future of orthodontics". 2005:1-6.

18- Salzmann JA. Orthodontics in daily practice, $1^{\text {st }}$ ed JB Lippincott Comp Philadelphia Toronto, 1974; 155: 294-96.

19 - Nanda R. Management of deep overbite malocclusion. In Nanda R, ed. Biomechanics and esthetic strategies in clinical Orthodontics. St Louis: WB Saunders, 2005: 131-55.

20 - Weiland FJ, Bantleon HP, and Droschl H. Evaluation of continuous arch and segmented arch leveling techniques in adult patients ,a clinical study. Am J Orthod Dentofac Orthop 1996; 110:647-52.

21- Goerigk BD, Wehrbein H. Intrusion of anterior teeth with the segmented arch technique of Burstone-a clinical study. Fort der Kiefirorthopadie 1992;53:16-25.

22- Carr WK. Segmented arch technique. J Clin Orthod. 1971 ; 9 : 493-509.

23-Dake LM, Sinclair PM. A comparison of the Ricketts and tweed type arch leveling techniques, Am J Orthod 1989; 95(1): 72-8.

24- Greig DG. Bioprogressive therapy: Overbite reduction with the lower utility arch Br J Orthod 1983;10: 214-16. 
25- Amasyali M, Sağdic D, Ölmez, Akin E, Karacay Ş. Intrusive Effects of the Connecticut Intrusion Arch and the Utility Intrusion Arch. Turk J Med Sci 2005; 35: 407-15.

26- Parker CD, Nanda RS, Currier GF. Skeletal and dental changes associated with the treatment of deep bite malocclusion. Am J Orthod Dentofacial Orthop. 1995; 107:382-93.

27- Cakirer B. Comparison of segmented arch technique and Bioprogressive Therapy in the treatment of deep bite [PhD thesis]. Ankara: University of Hacettepe; 1997.

28- Cleall JF, BeGole EA. Diagnosis and treatment of Class II division 2 malocclusion. Angle Orthod 1982; 52:38-60.

29- Shroff B, Lindauer SJ, Burstone CJ, and Jeffrey B. Segmented approach to simultaneous intrusion and space closure: Biomechanics of the three-piece base arch appliance. Am J Orthod Dentofac Orthod 1995;107:136-43.

30 - Uribe F, Nanda R. Treatment of Class II Division 2 Malocclusion in Adults: Biomechanical Considerations. J Clin Orthod 2003; 37:599-606. 